\title{
MICRO-MECHANICAL PROPERTIES OF CEMENT AND SLAG COMPOSITES MEASURED BY NANOINDENTATION
}

\author{
JIŘÍ NĚMEČEK $1 *$ *, JIŘÍ NĚMEČEK 2 \\ Czech Technical University in Prague, Faculty of Civil Engineering, Department of Mechanics, Thákurova 7, \\ 16629 Prague 6, Czech Republic \\ * corresponding author: jiri.nemecek.1@fsv.cvut.cz (Ph.D. candidate)
}

\begin{abstract}
In this study, the micromechanical response of two cementitious composites was characterized by nanoindentation. Pure Portland cement paste and Portland cement with 50 vol. \% replaced with granulated blast furnace slag (GBFS) paste were investigated at the age of 28 days. Grid nanoindentation, statistical deconvolution and scanning electron microscopy were used to characterize the main hydration products. Several grids with approximately 500 indents on each sample were performed to obtain modulus of elasticity, hardness and creep indentation parameter. Similar mechanical phases containing calcium silica hydrate, crystalline calcium hydroxide and un-hydrated clinker were found in both samples varying by volume fraction. Blended cement, moreover, contains a phase of slag hydration products with a significantly lower modulus of elasticity. This phase with a high portion of unreacted GBFS is mostly responsible for the difference of mechanical properties of the whole composite.
\end{abstract}

KEYWORDS: Nanoindentation, microstructure, blast furnace slag, cement paste.

\section{INTRODUCTION}

Concrete is one of the most used materials in the construction industry. One of its ingredients is Portland cement which is one of the major producers of carbon dioxide. In order to reduce the amount of cement used in concrete, admixtures are used. One of the most common admixtures is blast furnace slag which is created as a by-product of iron making as a liquid at $1350-1550{ }^{\circ} \mathrm{C}$. If this liquid is cooled rapidly, it forms a glass which is a latent hydraulic cement. Thus, using blast furnace slag is advantageous for two reasons, economical and ecological. Concrete which has uses slag has different properties such as decreased total heat evolution in massive structures, improved durability, slower compressive strength development [1] or decreased creep compliance 2 .

When Portland cement is mixed with water, the hydration process starts immediately. If the mixture is incorporated with slag, the hydration rate is much slower, and activators need to be present in the mixture. According to Chen [3], the most common activators are alkaline based e.g. Li, K, Na [4. In the later stages of hydration, slag reacts with Portlandite $(\mathrm{CH})$ in pozzolanic reaction. This results in different microstructure of slag blended cements which affects the macroscopic properties. Since the information about micromechanical properties is limited, obtaining more data would be beneficial. Some research has been done in terms of effect of thermal damage [5], $50 \%$ cement replacement; cured in moist condition for 120 days [6] or alkali activated slag [7].

\footnotetext{
${ }^{1} \mathrm{Ph}$. D. candidate at CTU in Prague

${ }^{2}$ Associate Professor at CTU in Prague
}

This study concentrates on the characterization of individual hydration products of pure Portland cement and cement with slag admixtures. Moreover, it compares the micromechanical response and creep parameters of individual hydration products.

\section{MATERIAL AND SAMPLE PREPARATION}

Two hydrated cement pastes for microstructural analysis were prepared. The first paste was made from pure Portland cement CEM I 42.5R (from Mokrá, Czech Republic), labeled PC. The second paste was mixed with 50 volume percent of CEM I 42.5R and 50 volume percent of blast furnace slag from Štramberk, labeled SL. Both pastes were mixed with water to binder ratio 0.4 and cast into cylindrical molds with height of $30 \mathrm{~mm}$ and diameter of $20 \mathrm{~mm}$. The samples were demolded after three days and put in the water for the next 25 days.

The samples were cut into $5 \mathrm{~mm}$ thick slices and dried at $50{ }^{\circ} \mathrm{C}$ for 24 hours. Then the surface of the samples was polished with $\mathrm{SiC}$ paper with grit sizes from 2000 to 4000. Lastly, the samples were put in ethanol in an ultrasonic cleaner to remove all free particles.

\section{Microstructural CHARACTERIZATION}

Individual chemical phases of cementitious composites were found and characterized by scanning electron microscopy (SEM) and energy dispersion X-ray spectroscopy (EDX). The sample PC (Fig. 1 a)) is primarily composed of three phases: Calcium-SilicaHydrate (C-S-H gel), crystalline calcium hydroxide - 

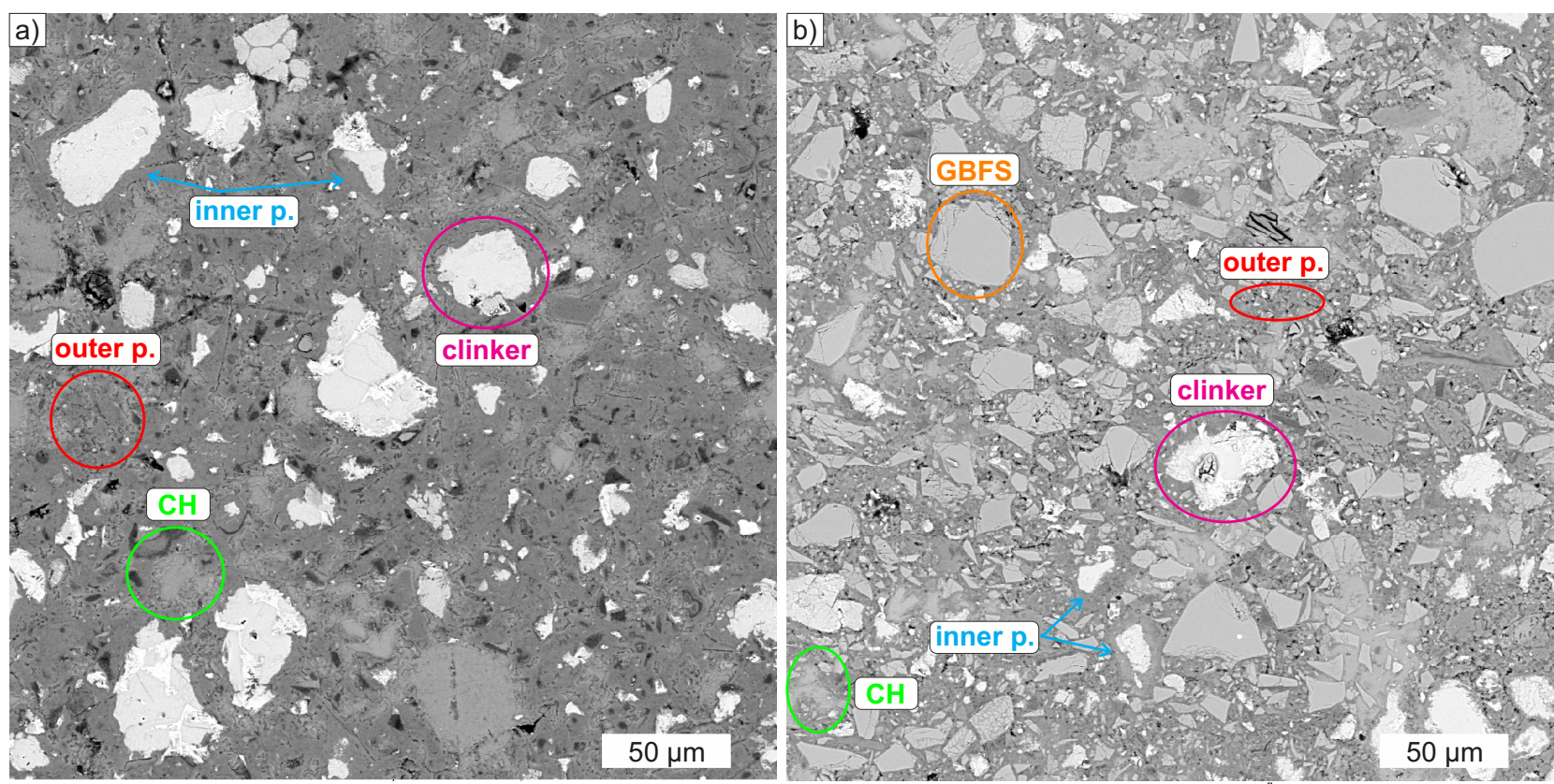

FIgurE 1. Typical SEM-BSE images of cement composites with highlighted phases a) PC b) SL.

\begin{tabular}{lccccc}
\hline Phase r. (\%) & Main hydrates & CH & GBFS & Clinker & Pores, cracks \\
\hline CP & 71.47 & 14.35 & - & 9.45 & 4.73 \\
CS & 51.53 & - & 34.02 & 7.74 & 6.71 \\
\hline
\end{tabular}

TABLE 1. Phase representation calculated from SEM-BSE images.

Portlandite $(\mathrm{CH})$ and anhydrous clinker. It is well documented that C-S-H gel exists with two packing densities called high density and low density [8]. Mixed with other hydration products, high density gel creates rims around the grains of unhydrated clinker called inner product. The outer product is created mostly of low density C-S-H gel mixed with other hydrates. The sample with slag SL (Fig. 1 b)) is composed of the same phases as the sample PC. Moreover, it includes unreacted GBFS and reaction product of the slag which is mostly C-S-H gel where some silica is replaced by alumina to form C-A-S-H gel [7]. Also, both samples contain minor phases such as ettringite, hydrogarnet and monosulfphate which were not detected on polished surfaces by images analysis.

The image analysis can make a histogram for all the different phases in the images based on their grey levels from which it is possible to calculate the volume fraction of the identified major chemical phases. Twelve SEM images with a view field of $300 \times 300 \mu \mathrm{m}$ were used for the analysis. The results are summarized in Table 1 On both samples, cracks and porosity were visible which corresponds to the color black. Due to similar color intensity of inner and outer products, both phases were combined and labeled as main hydrates. Also, low amount of $\mathrm{CH}$ in sample SL makes it impossible to separate them. Thus, $\mathrm{CH}$ was grouped with GBFS.

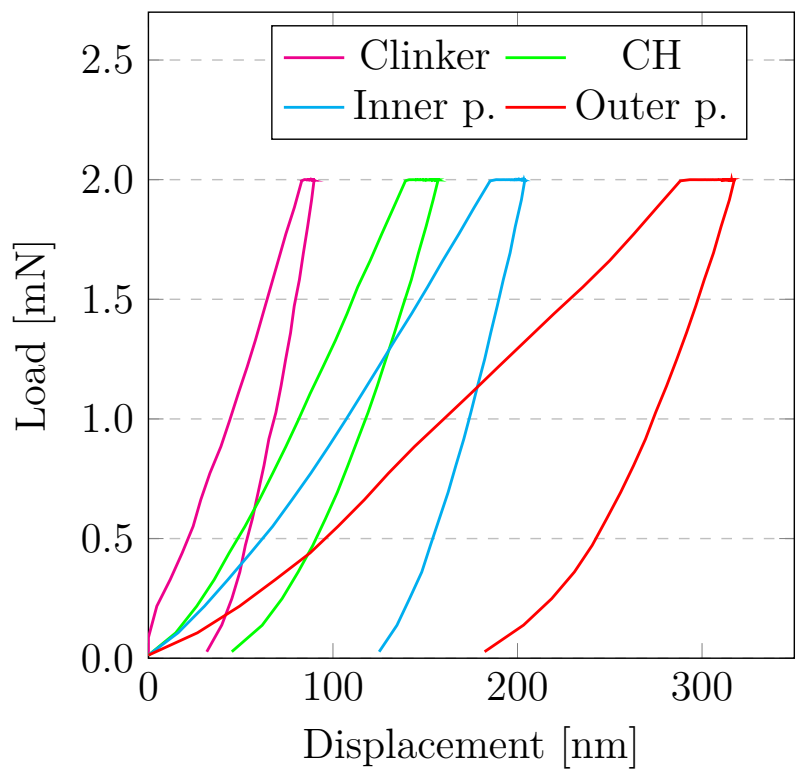

Figure 2. Typical load-displacement curves.

\section{NANOINDENTATION}

Micromechanical properties such as modulus of elasticity or hardness of individual chemical phases can be measured by nanoindentation. A principle of nanoindentation is based on pressing a tip with known properties into a material at small scale. Hysitron Tribolab TI-700 with Berkovich diamond tip was used for test- 

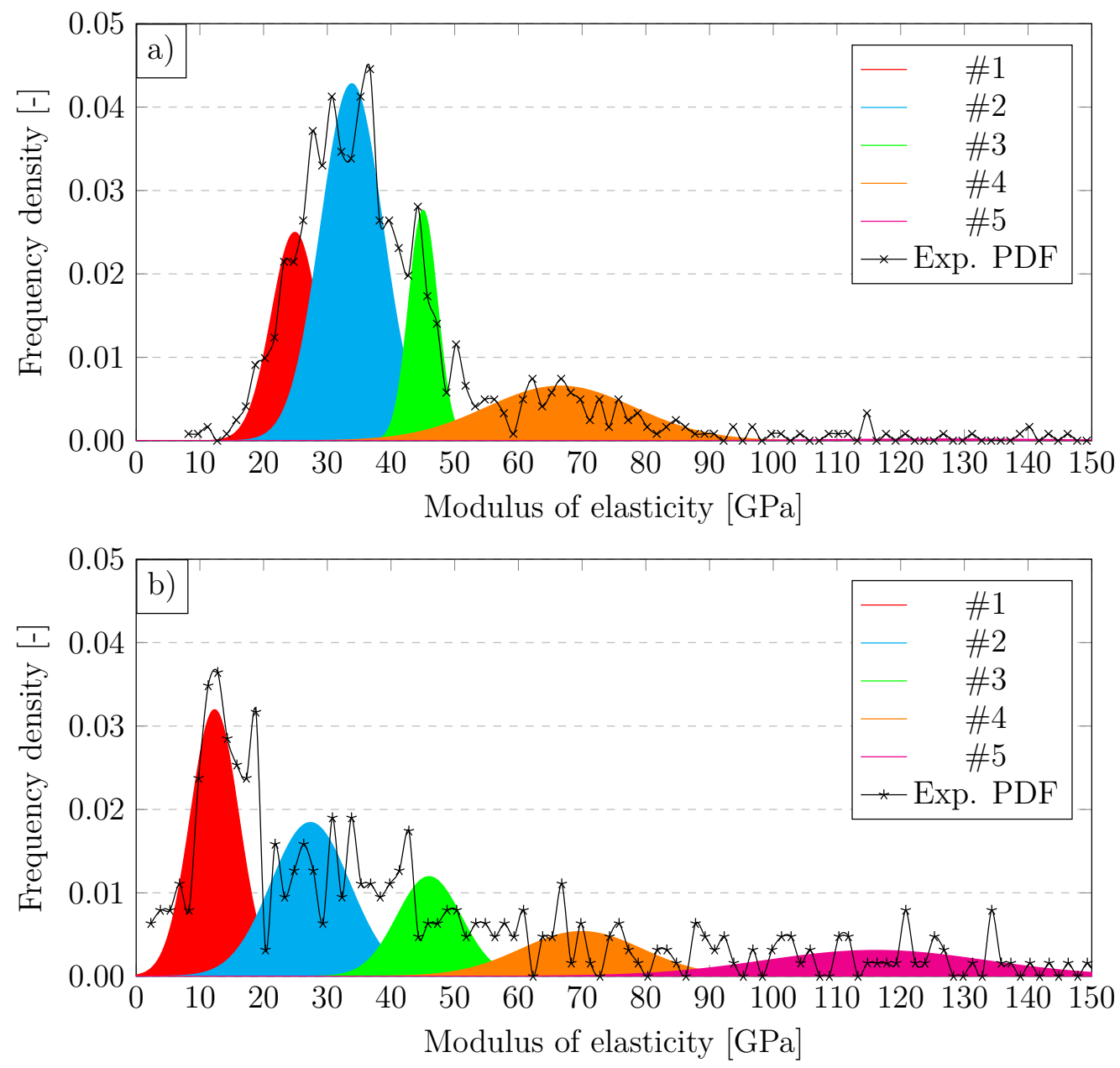

Figure 3. Frequency plots of the samples a) PC b) SL. The bin-size for deconvolution of modulus of elasticity $E=1.5 \mathrm{GPa}$.

ing. Five grids of $10 \times 10$ indents with regular spacing of $12.5 \mu \mathrm{m}$ were prescribed on both samples in order to cover heterogeneity of the samples. Trapezoidal loading diagram was prescribed with a linear loading up to $2 \mathrm{mN}$ at a constant rate of $40 \mathrm{mN} / \mathrm{min}$, followed by 20 seconds holding period and linear unloading same rate as loading. During the measurement, load displacement curves are measured. The typical curves are shown in Fig. 2

Indentation modulus was evaluated from load displacement diagram using the Oliver and Pharr method [9]. The method is based on Sneddon solution [10] of a rigid indenter action on an elastic half space. The indentation modulus $E_{r}$, and hardness $H$, are given as

$$
\begin{gathered}
E_{r}=\frac{S \sqrt{\pi}}{2 \beta \sqrt{A_{c}}}, \\
H=\frac{P_{\max }}{A_{c}},
\end{gathered}
$$

where $S$ represents elastic unloading stiffness, $A_{c}$ is the projected contact area, $\beta$ is coefficient which considers different geometry of the indentation tip $(\beta=1.304$ for Berkovich tip) and $P_{\max }$ is the maximum load. Indentation modulus represents a combination of elastic stiffness of the sample and the tip. Modulus of elasticity $E$, of the sample can be obtained from equation

$$
\frac{1}{E_{r}}=\frac{1-\nu^{2}}{E}+\frac{1-\nu_{i}^{2}}{E_{i}}
$$

where $E_{i}$ and $\nu_{i}$ are modulus of elasticity and Poisson's ratio of the indentation tip (for the diamond tip $E_{i}=1141 \mathrm{GPa}$ and $\left.\nu_{i}=0.07\right), \nu$ is the Poisson's ratio of the sample, it was assumed as 0.2 for the cement paste.

Analysis of the large amount of data produced by grid indentation is possible due to a technique known as statistical deconvolution. Using deconvolution technique, it is possible to evaluate and separate the mechanical response of the individual phases in cementitious composites and identify volume fraction. This method is frequently used for heterogenous systems as it was also successfully done on cementitious material, e.g. [8, 11]. 


\begin{tabular}{llccccc}
\hline & & $\# 1$ & $\# 2$ & $\# 3$ & $\# 4$ & $\# 5$ \\
\hline $\mathrm{PC}$ & $E[\mathrm{GPa}]$ & $24.9 \pm 3.7$ & $33.8 \pm 4.8$ & $45.0 \pm 2.2$ & $66.6 \pm 11.6$ & $127.1 \pm 18.9$ \\
& $H[\mathrm{GPa}]$ & $1.10 \pm 0.21$ & $1.71 \pm 0.19$ & $2.29 \pm 0.16$ & $3.68 \pm 1.07$ & $10.88 \pm 2.39$ \\
& $C I T[\%]$ & $11.3 \pm 3.1$ & $9.5 \pm 3.3$ & $6.4 \pm 3.7$ & $4.9 \pm 3.1$ & $2.1 \pm 1.9$ \\
& vol. $f .[\%]$ & 23.0 & 42.0 & 15.5 & 18.1 & 1.4 \\
$\mathrm{CS}$ & $E[\mathrm{GPa}]$ & $12.3 \pm 3.7$ & $27.4 \pm 6.2$ & $45.9 \pm 5.0$ & $69.9 \pm 9.5$ & $116.1 \pm 14.4$ \\
& $H[\mathrm{GPa}]$ & $0.56 \pm 0.53$ & $1.55 \pm 0.64$ & $2.24 \pm 0.95$ & $3.50 \pm 1.21$ & $6.24 \pm 1.98$ \\
& $C I T[\%]$ & $12.1 \pm 3.2$ & $9.3 \pm 3.1$ & $8.7 \pm 2.2$ & $6.8 \pm 4.1$ & $5.2 \pm 2.8$ \\
& vol. $f .[\%]$ & 30.2 & 28.5 & 15.0 & 12.8 & 13.5 \\
\hline
\end{tabular}

TABLE 2. Mean values and standard deviation of individual deconvoluted phases of modulus of elasticity, hardness, CIT and volume fraction.

Short-time creep of material can be evaluated from holding period as indentation creep parameter CIT is given by equation

$$
\operatorname{CIT}_{\left(P, t_{1}, t_{2}\right)}=\frac{h_{2}-h_{1}}{h_{1}} \times 100,
$$

which is defined as the relative change of indentation depths $h_{1}$ and $h_{2}$ encountered at times $t_{1}$ and $t_{2}$, respectively. The parameter is dependent on contact force $P_{\max }$ and time which is kept during the holding period.

\section{Results AND DISCUSSION}

Statistical deconvolution was used on experimental data of modulus of elasticity to calculate the mechanical phases of the samples. Since the measured mechanical response is related to the finite indentation volume, the individual mechanical phases were assigned to the most probable chemical composition.

Both samples were separated into five mechanically similar phases. In sample PC (Fig. 3a)), Phase \#1, contains mostly outer product. The main phase, labeled \#2 is primarily formed by inner product, however, the Gauss peak overlaps with neighboring phases thus, this phase also contains some portion of outer product and Portlandite. \#3 includes primarily Portlandite and small amount of un-hydrated clinker particles. Phases \#4 and \#5 were deconvoluted with modulus of elasticity higher than $50 \mathrm{GPa}$ which belongs only to un-hydrated clinker, these stiff particles ordinarily have $E=110-160 \mathrm{GPa}[12$. Such a high modulus was obtain only for clinker of higher dimension in phase \#5. Residual clinker of smaller dimension, while loaded, interacts with surrounding matrix of C-S-H gel resulting in lower modulus of elasticity 50-100 GPa in phase \#4. In sample SL (Fig. 3 b)) phase \#1, is similar to more porous outer product composed with $\mathrm{C}-\mathrm{A}-\mathrm{S}-\mathrm{H}$ gel and slag hydration products. Phase \#2 is mostly formed by C-S-H gel, mostly inner product. \#3 includes Portlandite and small particles of GBFS. Phases \#4 and \#5 are created with same composition as sample PC moreover both phases contain particles of GBFS. The results of the statistical deconvolution for both samples are shown in Fig. 3 and values of the modulus of elasticity, hardness, CIT and volume fraction are summarized in Table 2

Phase \#2 is the most dominant for sample PC with $(E=33.8 \pm 4.8 \mathrm{GPa})$ which is comparable to phase \#2 of sample SL $(E=27.4 \pm 6.2 \mathrm{GPa})$, the higher value for sample $\mathrm{PC}$ is due to the presence of Portlandite in this phase. Phase \#1 deconvoluted in sample PC still has a higher modulus and compared to phase \#1 in sample SL with volume fraction of $30.2 \%$. This shift is visible in Fig. 4. Phase \#3 present in sample SL belongs to Portlandite with $E=45.0 \mathrm{GPa}$ (according to literature $E=43.9 \mathrm{GPa},[11]$ ), also identified volume fraction differs with SEM image analysis only about $1.15 \%$ which is in good correlation. Phase \#3 of sample SL is created by different chemical phases, however, the mechanical response and volume fraction is almost identical to sample PC. The volume fraction of stiffer particles $(E>50 \mathrm{GPa})$ is $6.8 \%$ higher in sample SL. The difference in volume fraction is even more visible for larger particles with $E=100 \mathrm{GPa}$. The results of hardness correlates with modulus of elasticity, as well as CIT parameter which is the highest for outer product followed by inner product. $\mathrm{CH}$, GBFS and residual clinker do not creep and values are dependent on their dimension floating in C-(A)-S-H matrix.

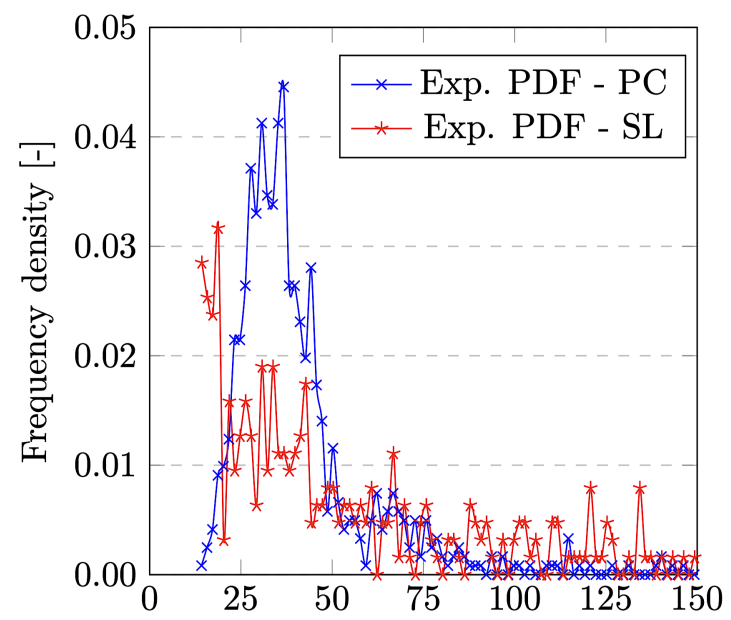

Figure 4. Probability distribution graph of modulus of elasticity of the PC and SL samples 
Thus, there are two major significant differences between both samples. First one is the presence of phase \#1 in sample SL with modulus of elasticity $(\mathrm{E}=12.3 \pm 3.7 \mathrm{GPa})$ and volume fraction of $30.2 \%$. This value corresponds well with literature results, the $\mathrm{NaOH}$ activated slag with $E=12-20 \mathrm{GPa}$ [7] and slag blended cement measured in 120 days, where $E=15.5 \mathrm{GPa}$ 6. Second is the high portion of unreacted GBFS in SL sample which is spread to the phases \#3 - \#5 with total volume fraction $41.3 \%$ this corresponds to results from image analysis $41.76 \%$ (GBFS + Clinker).

According to study of Shaikh [13] which studied macroscopic properties of 28 days old slag blended cement pastes, the compressive strength up to $70 \%$ slag replacement is increased for blended pastes compared to ordinary Portland cement paste. The compressive strength of the whole sample is affected by the microstructure with porosity distribution and other defects. From our microstructure investigation it is highly probable that high volume fraction of unreacted slag particles contributes to higher compressive strength of sample SL. The strength was, however, not assessed in this work.

\section{Conclusions}

Microstructure of Pure Portland cement (PC) and cement with slag admixture (SL) was characterized by SEM images, EDX and nanoindentation. According to EDX, sample SL contains two additional chemical phases over the sample PC, C-(A)-S-H gel and unreacted GBFS. Lower volume fraction of Portlandite of sample SL was observed by SEM image analysis and nanoindentation which confirms consumption of the slag in hydration reaction. The main hydrated material of sample SL has significantly lower modulus of elasticity and hardness than sample PC. Both samples contain un-hydrated material stiffening the samples. The volume fraction of un-reacted particles identified by nanoindentation is almost two times higher for sample SL.

CIT parameter of all phases of sample SL, except the inner product, reaches higher values than sample PC, meaning sample SL exhibits more compliant response. The values of CIT parameter of un-hydrated particles are dependent on their dimension floating in C-(A)-S-H matrix and must not be treated as intrinsic phase properties.

\section{ACKNOWLEDGEMENTS}

Financial support of the Czech Science Foundation (project 17-05360S) and the Grant Agency of the Czech Technical University in Prague (SGS18/114/OHK1/2T/11) are gratefully acknowledged.

\section{REFERENCES}

[1] H. F. Taylor. Cement chemistry. Thomas Telford, 1997. DOI:10.1680/cc.25929

[2] I. Pane, W. Hansen. Early age creep and stress relaxation of concrete containing blended cements. Materials and Structures 35(2):92, 2002. DOI:10.1007/BF02482107.

[3] W. Chen, H. Brouwers. The hydration of slag, part 2: Reaction models for blended cement. Journal of Materials Science 42:444-464, 2007. DOI:10.1007/s10853-006-0874-1

[4] B. Kolani, L. Buffo-Lacarrière, A. Sellier, et al. Hydration of slag-blended cements. Cement and Concrete Composites 34:1009-1018, 2012. DOI:10.1016/j.cemconcomp.2012.05.007

[5] V. Z. Zadeh, C. P. Bobko. Nanoscale mechanical properties of concrete containing blast furnace slag and fly ash before and after thermal damage. Cement and Concrete Composites 37:215 - 221, 2013. DOI:10.1016/j.cemconcomp.2012.09.003

[6] C. Hu, Z. Li, Y. Gao, et al. Investigation on microstructures of cementitious composites incorporating slag. Advances in Cement Research 26:222-232, 2014. DOI:10.1680/adcr.13.00029.

[7] F. Puertas, M. Palacios, H. Manzano, et al. A model for the c-a-s-h gel formed in alkali-activated slag cements. Journal of the European Ceramic Society 31(12):2043 2056, 2011. DOI:10.1016/j.jeurceramsoc.2011.04.036.

[8] G. Constantinides, F.-J. Ulm. The nanogranular nature of c-s-h. Journal of the Mechanics and Physics of Solids 55(1):64-90, 2007. DOI:10.1016/j.jmps.2006.06.003

[9] W. C. Oliver, G. M. Pharr. An improved technique for determining hardness and elastic modulus using load and displacement sensing indentation experiments. Journal of materials research 7(6):1564-1583, 1992. DOI:10.1557/JMR.1992.1564.

[10] I. N. Sneddon. The relation between load and penetration in the axisymmetric boussinesq problem for a punch of arbitrary profile. International journal of engineering science 3(1):47-57, 1965. DOI:10.1016/0020-7225(65)90019-4

[11] J. Němeček, V. Králík, J. Vondřejc. Micromechanical analysis of heterogeneous structural materials. Cement and Concrete Composites 36(0):85 - 92, 2013. DOI:10.1016/j.cemconcomp.2012.06.015

[12] K. Velez, S. Maximilien, D. Damidot, et al. Determination by nanoindentation of elastic modulus and hardness of pure constituents of portland cement clinker. Cement and Concrete Research 31(4):555-561, 2001. DOI:10.1016/S0008-8846(00)00505-6

[13] F. U. A. Shaikh, A. Hosan. Effect of nano silica on compressive strength and microstructures of high volume blast furnace slag and high volume blast furnace slag-fly ash blended pastes. Sustainable Materials and Technologies 20:e00111, 2019. DOI:10.1016/j.susmat.2019.e00111. 